\title{
The Impact of Deep Brain Stimulation on the Quality of Life and Swallowing in Individuals with Parkinson's Disease
}

\author{
Maira Rozenfel Olchik ${ }^{1} \quad$ Marciéle Ghisi ${ }^{2}$ Annelise Ayres ${ }^{3}$ Arthur Francisco Shumacher Schuh ${ }^{4}$ \\ Paulo Petry Oppitz ${ }^{5}$ Carlos Roberto de Mello Rieder ${ }^{6,7}$
}

\footnotetext{
${ }^{1}$ Departament of Surgery and Orthopedics, Universidade Federal do Rio Grande do Sul, Porto Alegre, RS, Brazil

${ }^{2}$ Graduation in Speech Therapy, Universidade Federal do Rio Grande do Sul, Porto Alegre, RS, Brazil

3 Post-Graduation Program in Health Sciences, Universidade Federal de Ciências da Saúde de Porto Alegre, Porto Alegre, RS, Brazil

${ }^{4}$ Departament of Pharmacology, Universidade Federal do Rio Grande do Sul, Porto Alegre, RS, Brazil

${ }^{5}$ Neurosurgery Service, Hospital de Clínicas de Porto Alegre, Porto Alegre, RS, Brazil

6 Medical School, Universidade Federal de Ciências da Saúde de Porto Alegre, Porto Alegre, RS, Brazil

7 Department of Neurology and Movement Disorders, Hospital de Clínicas de Porto Alegre, Porto Alegre, RS, Brazil
}

\author{
Address for correspondence Maira Rozenfeld Olchik, PhD, \\ Departamento de Cirurgia e Ortopedia, UFRGS, Av. Ramiro Barcelos, \\ 2492, Porto Alegre, RS, 90035-007, Brasil \\ (e-mail: mairarozenfeld@hotmail.com).
}

Int Arch Otorhinolaryngol 2018;22:125-129.

\begin{abstract}
\section{Keywords}

- neurology

- speech therapy

- swallowing

- parkinson's disease

- deep brain stimulation

Introduction Deep brain stimulation (DBS) is an established treatment for Parkinson's disease (PD). However, there is little evidence regarding the effect of DBS on dysphagia. Objective To assess the swallowing and quality of life of individuals with PD before and after DBS surgery.

Methods Our sample consisted of people who had undergone DBS surgery in a referral hospital in the state of Rio Grande do Sul, Brazil. The inclusion criteria were a diagnosis of PD and having undergone DBS surgery. A cognitive screening, through a questionnaire about depression and quality of life, was conducted. Evaluations of each patient's swallowing were performed before and after surgery. The assessment consisted of anamnesis, clinical assessment, the Functional Oral Intake Scale, clinical evaluation of swallowing, and the Hoehn and Yahr scale.

Results The sample included 10 individuals, all male, with a mean age of 57.3 years $( \pm 4.7)$, a mean disease duration of 13.0 years $( \pm 2.4)$, and mean level education of 8.1 years $( \pm 4.0)$. In the clinical evaluation of the swallowing, a significant improvement after DBS was not observed. However, little changes in the signs and symptoms of dysphagia that had a positive impact on the quality of life were observed. Furthermore, there was no relation between the patients' motor subtype and swallowing pre- and post-DBS.

Conclusion There was an improvement in the quality of life of the patients after DBS. However, the improvement in the clinical signs and symptoms of dysphagia did not cause an overall improvement in the swallowing function.
\end{abstract}

received

November 12, 2016

accepted

March 21, 2017

published online

June 5, 2017
DOI https://doi.org/

10.1055/s-0037-1603466. ISSN 1809-9777.
Copyright $\odot 2018$ by Thieme Revinter

Publicações Ltda, Rio de Janeiro, Brazil
License terms

(c) (i) $\ominus$ (\$) 


\section{Introduction}

Deep brain stimulation (DBS) of the subthalamic nucleus (STN) is an established treatment for Parkinson's disease (PD). The beneficial effects of DBS in reducing motor symptoms in individuals with PD are robust, and have been reported in the literature. ${ }^{1-3}$ However, there is little evidence regarding the effect of DBS on the non-motor symptoms of $\mathrm{PD}$, such as dysphagia. ${ }^{1,4-6}$

According to the literature, dysphagia may occur independently of the phase of PD, and have a prevalence of 31\% to $100 \%$ of patients with PD. ${ }^{7}$ Among the clinical signs of dysphagia observed in patients with PD are: increased oral transit time; difficulty in forming the bolus; residue in the oral cavity; weak ejection of the bolus; multiple swallows; posterior escape of the bolus, reflecting decreased swallowing; change in the closing of the vocal folds; reduction in pharyngeal and esophageal motility; food stasis in the pharynx; laryngeal penetration and aspiration; dysfunction of the esophageal sphincter; and gastro-esophageal reflux. $^{8-11}$

Some complications that may be caused by dysphagia are: malnutrition; dehydration; and aspiration pneumonia. Pneumonia is the most common cause of death in patients with PD. ${ }^{12}$

Various screening tests, including clinical evaluations of pulse oximetry, have been used to detect silent aspiration. These tests have sensitivities of 27 to $100 \%$, and specificities of 39 to $97 \%$. Thus, the clinical evaluation of dysphagia is important. $^{13}$

Existing studies on DBS claim that the surgery does not negatively affect swallowing, but there is still no evidence that it is an effective form of treatment for dysphagia in patients with PD. ${ }^{1,14-16}$ In the studies by Ciucci et $\mathrm{al}^{14}$ and Lengerer et $\mathrm{al}^{15}{ }^{15}$ no significant change in the swallowing evaluation after the completion of DBS was observed. Corroborating these findings, Kulneff ${ }^{1}$ also did not observe clinical changes in swallowing, but found an improved selfevaluation of swallowing after DBS. However, the Silbergleit study ${ }^{16}$ reported improvements in oral motor control of the oropharynx regarding solid food consistency. It thus appears that the evidence for the effects of DBS on dysphagia is still inconclusive and conflicted. The objective of this study is to compare the swallowing and quality of life of individuals with PD before DBS surgery to their swallowing after DBS surgery.

\section{Material and Methods}

We performed a longitudinal descriptive study. Our sample consisted of people who had undergone bilateral DBS of the subthalamic nucleus between January 2014 and March 2015 in a referral hospital in the city of Porto Alegre, Rio Grande do Sul, Brazil. All individuals who had undergone surgery during this period participated in the research. The inclusion criteria were a diagnosis of PD according to the United Kingdom Parkinson's Disease Society Brain Bank criteria for idiopathic $\mathrm{PD}^{17}$ and having undergone DBS surgery. All participants were informed of the purpose of the research, and signed an informed consent form. The study was approved by the research ethics committee of the hospital.

\section{Procedures}

The following procedures were performed before (a maximum of thirty days) and after (between six months to one year) the surgery: anamnesis, clinical evaluation, evaluation using the the Functional Oral Intake Scale (FOIS), staging of PD using the Modified Hoehn and Yahr (H\&Y) scale, and classification of the motor subtype of the patient as either hard/akinetic or trembling based on a records review. The motor subtype assessments were performed by a neurologist who is an expert in movement disorders. The anamnesis was used to gather information regarding age, gender, education, and duration of the disease.

These procedures were performed in two stages (pre- and post-surgically), and were designed to not only observe a single moment of swallowing during an objective examination, but also to assess functionally how the patients ate a full meal by checking for the clinical signs of dysphagia described below.

The clinical evaluation of swallowing was performed by a certified speech therapist, previously trained to apply the protocols. All the assessments were conducted by the same professional. This assessment had the purpose of checking for signs and symptoms of oropharyngeal dysphagia. We used solid food consistency (half portion of bread) and liquid ( $100 \mathrm{~mL}$ of water) evaluated by free demand using cervical auscultation and an oximeter. The signs and symptoms were analyzed based on the literature on this field. ${ }^{18,19}$ We assessed the presence or absence of coughing, gagging, tongue projection, side head projection, head projection, noise, food residue, periorbicular contraction, and lip interposition. ${ }^{14,16,20}$

At the end of the clinical evaluation, the intake of food was scored according to the FOIS. This scale scores the level of oral food intake of the patients at particular levels, from 0 (restricted to alternative food pathway) to 7 (total oral intake without restrictions), with the aim of monitoring the patients' evolution during the therapeutic process. The valid and reliable instrument has a coefficient of inter-rater reliability that ranges from 0.98 to 0.99 , with Kappa coefficient average values between 0.86 and 0.91 , with appropriate consensual validity (Kendall 0,90 agreement) and criterion validity (based on The Mann Assessment of Swallowing Ability). ${ }^{21} \mathrm{~A}$ translated and validated version for Brazilian Portuguese was used. ${ }^{22}$ At the end of the evaluation, the swallowing of the individual was classified as:

- Normal: normal for both consistencies and all items.

- Functional: it can be normal or changed, but does not result in worsening efficiency of swallowing or aspiration; it is possible to maintain adequate nutrition and hydration orally.

- Dysphagia: when there is a risk of penetration and laryngeal aspiration. 
Table 1 Sociodemographic and clinical profile pre- and post DBS

\begin{tabular}{|l|l|l|l|l|l|l|l|l|l|}
\hline & Age & Level of & Disease duration & H\&Y & Motor & FOIS & \multicolumn{2}{l|}{ Swallowing } \\
\cline { 6 - 10 } & & & & & & Pre & Post & Pre & Post \\
\hline 01 & 60 & 2 & 14 & 3 & Rigid & 7 & 7 & Functional & Functional \\
\hline 02 & 54 & 4 & 14 & 4 & Tremor & 7 & 7 & Dysphagia & Functional \\
\hline 03 & 64 & 5 & 12 & 2 & Tremor & 7 & 7 & Dysphagia & Functional \\
\hline 04 & 49 & 15 & 10 & 3 & Rigid & 7 & 7 & Functional & Dysphagia \\
\hline 05 & 52 & 7 & 15 & 3 & Rigid & 4 & 4 & Dysphagia & Dysphagia \\
\hline 06 & 56 & 12 & 8 & 2 & Rigid & 7 & 7 & Dysphagia & Dysphagia \\
\hline 07 & 63 & 6 & 15 & 3 & Rigid & 7 & 7 & Dysphagia & Functional \\
\hline 08 & 56 & 8 & 13 & 3 & Tremor & 6 & 4 & Dysphagia & Dysphagia \\
\hline 09 & 60 & 10 & 16 & 3 & Rigid & 7 & 7 & Functional & Functional \\
\hline 10 & 59 & 12 & 13 & 3 & Rigid & 7 & 7 & Functional & Functional \\
\hline
\end{tabular}

Abbreviations: DBS, deep brain stimulation; FOIS, Functional Oral Intake Scale; H \& Y, Hoehn \& Yahr staging Scale.

To classify the patients' stage of PD, we used the H\&Y Degree of Disability Scale, which has the purpose of indicating the general state of the patient. It consists of five classification stages used to assess the severity of PD, and it essentially measures global signs and symptoms. ${ }^{23}$

The instruments Parkinson Disease Questionnaire-39 (PDQ-39), translated to Portuguese, and the Beck Depression Inventory (BDI) were applied. These tests were used to verify the influence of depression and quality of life in the swallowing function.

We performed a descriptive analysis of the data for the continuous variables (age, education, disease duration, PDQ39, BDI, and FOIS). The results were expressed as means and standard deviations (SDs). For the nominal variables, which were swallowing and signs and symptoms of dysphagia, the results were presented as percentages. We used McNemar's test to assess the differences between the signs and symptoms of dysphagia pre- and post-DBS. The analyses were performed using the Statistical Package for the Social Sciences (SPSS, SPSS Inc., Chicago, IL, US) software, version 18.0. All tests were stipulated to have a $5 \%$ error.

\section{Results}

Our sample consisted of 10 male individuals, $63.6 \%$ were married. The average age was 57.3 years $( \pm 4.7)$, the mean duration of the disease was 13.0 years $( \pm 2.4)$, and the mean level of education was 8.1 years $( \pm 4.0)$.

Concerning the motor symptoms, clinical improvement was observed in all patients after DBS during a medical evaluation, and no modification was associated with the motor subtype (postural tremor and rigidity). This information was extracted from the patients' medical records. The levodopa equivalent dose was not modified before and after surgery during the period of this study.

- Table 1 contains the patients' sociodemographic information and their clinical and swallowing profiles.

As shown in - Table 2, we observed no significant differences in the presence or absence of signs and symptoms of dysphagia before and after surgery.

We observed a positive impact of DBS on the quality of life of the individuals. Regarding depression and cognitive

Table 2 Findings in the swallowing evaluation pre and post-DBS

\begin{tabular}{|l|l|l|l|}
\hline Signals and symptoms & $\begin{array}{l}\text { Pre } \\
\mathbf{n}(\%)\end{array}$ & $\begin{array}{l}\text { Post } \\
\mathbf{n}(\%)\end{array}$ & $p$ \\
\hline Alteration of orbicular contraction & $6(60)$ & $1(10)$ & 0.063 \\
\hline Alteration in mentalis contraction & $3(30)$ & $1(10)$ & 0.5 \\
\hline Head movement & $6(60)$ & $2(20)$ & 0.219 \\
\hline Noise during swallowing & $5(50)$ & $4(40)$ & 1.00 \\
\hline Residue after swallowing & $4(40)$ & $5(50)$ & 1.000 \\
\hline Tongue projection during swallowing & $4(40)$ & 0 & $*$ \\
\hline Choking during swallowing & $3(30)$ & $2(20)$ & 1.000 \\
\hline Coughing during swallowing & $1(10)$ & $2(20)$ & 1.000 \\
\hline
\end{tabular}

Abbreviation: DBS, deep brain stimulation.

Notes: McNemar's test; ${ }^{*}$ we could not perform statistical tests; e = sample. 


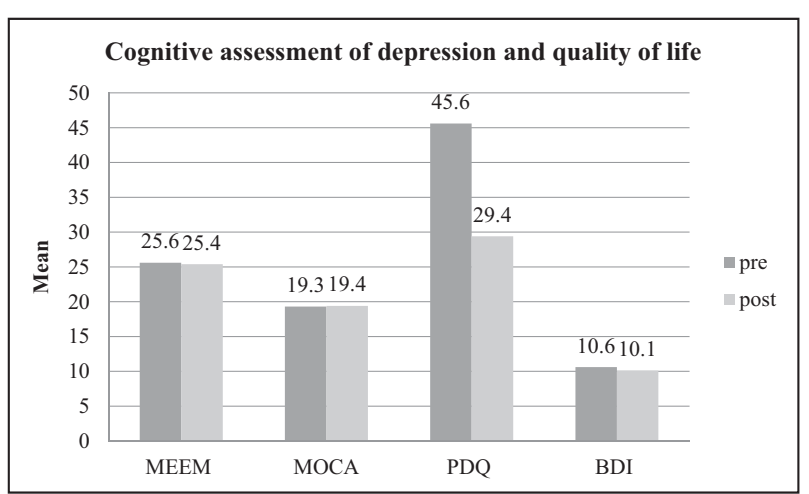

Fig. 1 Comparison of cognitive assessment, depression, and quality of life pre- and post-DBS. Abbreviations: BDI, beck depression inventory; PDQ, Parkinson disease questionnaire; MMSE, mini mental state examination; MOCA, Montreal cognitive assessment.

aspects, we observed no changes between pre- and post-DBS. These data are presented in -Fig. 1.

\section{Discussion}

Our results demonstrate that there was no significant improvement in swallowing in the patients after DBS. These findings corroborate those reported in the literature, $1,3,14$ and indicate that there are no significant changes in the swallowing evaluation in the patients after DBS. Previous studies, however, did not address a possible relationship between the effects of DBS on the triad of PD motor symptoms and post-surgery swallowing. They also did not report whether patients with tremor motor symptoms had patterns of swallowing pre- or post-DBS that differed from those of patients who had postural tremor and rigidity. As in our study, the motor subtype was not associated with swallowing.

However, the patients showed mild changes in the clinical evaluation that interfered with the improvement in their quality of life.

With the motor improvements, the patients decreased the oropharyngeal compensation during the feeding process. Six patients had their orbicular contraction changed pre-DBS, and just kept those changes post-DBS. Regarding the head movement, six patients had preoperatively, which can cause a new exhaust feed and only two maintained postoperatively.

Some studies ${ }^{1,3,14,24}$ with samples similar to ours and one study with a larger sample ( 18 subjects) ${ }^{3}$ indicate that there is a maintenance of the standard swallowing pattern after the completion of the DBS, regardless of the position of the electrodes and the stimulator settings (amplitude, frequency, pulse width). Even though the aforementioned studies found improvements in some aspects of swallowing and tongue movement, including in the swallowing reflex during the laryngeal phase and the pharyngeal transit time, none found overall improvements in swallowing. The same was observed in our study. Even though clinically an improvement in swallowing due to an improvement in motor aspects was expected, perhaps a long-term follow-up of these patients in order to determine the effect of the motor issues in swallowing is necessary.

In the literature review, the articles that evaluate swallowing and $\mathrm{DBS}^{1,3,14,24}$ do not mention the individual parameters of each patient; the only article that refers to the parameters describes them in function of evaluating with DBS on and off. The parameters are different in each patient, and because of our small sample, it was not possible for us to evaluate the correlation with these data. According to the following parameters, there is no first and post-surgery, the data are being collected, and the new evaluation of swallowing will be performed later.

In the study analyzing post-DBS swallowing with the largest sample so far, Lengerer et al ${ }^{15}$ used videofluoroscopy to analyze 18 subjects without dysphagia who underwent DBS in the pre-operative period, and suggested a little improvement in swallowing after surgery. Even though they observed a significant decrease of up to $70 \%$ in the late pharyngeal reflex, a decline by up to $16 \%$ in pharyngeal transit time after surgery was observed. The pharyngeal reflex time decreased by up to $18 \%$ following DBS. Moreover, the duration of the opening of the cricopharyngeus was decreased by up to $21 \%$ after the operation.

These results were also corroborated by a study by Kitashima et $\mathrm{al}^{3}$ in which there was some improvement in the signs and symptoms of dysphagia without an improvement in the overall function of swallowing.

We observed an improvement in the total quality of life (QoL) scores following DBS, which is in agreement with the studies by Volkmann et $\mathrm{al}^{25}$ and Tykocki et $\mathrm{al}^{26}$, who found a significant reduction in the depressive symptoms and motor signs, and an improved QoL in patients with PD after DBS.

Even though these studies compare QoL before and after DBS, 25-27 they do not analyze swallowing in the same manner as we do here. However, since swallowing is a factor with a significant impact on QoL, it is evident that we need to analyze it in studies of QoL.

We found no significant changes in the average BDI score after DBS. Our findings corroborate previous reports in the literature, ${ }^{28-32}$ which indicate that there are no significant variations in the symptoms of depression after DBS. The same is observed when comparing individuals with PD who have undergone DBS with those who have not undergone DBS. Aono et $\mathrm{al}^{33}$ noted an improvement in the depressive symptoms one month after DBS. However, this improvement was not sustained over the period of one year, and was not correlated with the state of motor function. Thus, the findings regarding the effects of DBS on depressive symptoms are inconclusives.

\section{Conclusion}

We concluded that there was an improvement in the QoL of the patients after DBS. However, the decrease of the clinical signs and symptoms of dysphagia did not impact the overall improvement in the swallowing function. Additionally, we observed the relationship between PD motor subtype and swallowing pre- and post-DBS in this sample. 


\section{References}

1 Kulneff L, Sundstedt S, Olofsson K, et al. Deep brain stimulation effects on swallowing function in Parkinson's disease. Acta Neurol Scand 2013;127(05):329-336

2 Weaver FM, Follett K, Stern M, et al; CSP 468 Study Group. Bilateral deep brain stimulation vs best medical therapy for patients with advanced Parkinson disease: a randomized controlled trial. JAMA 2009;301(01):63-73

3 Kitashima A, Umemoto G, Tsuboi Y, Higuchi MA, Baba Y, Kikuta T. Effects of subthalamic nucleus deep brain stimulation on the swallowing function of patients with Parkinson's disease. Parkinsonism Relat Disord 2013;19(04):480-482

4 Gasperim AZ, Jurkiewicz AL, Marques JM, Santos RS, Marcelino PCO, Junior FH. Deglutição e Tosse nos Diferentes Graus da Doença de Parkinson. Arq Int Otorrinolaringol 2011;15:181-188

5 Liszbinski RB, Sulczewski FB, Stefani DFV, Coelho FH. Doença de Parkinson: o fenótipo em idosos. Revista Contexto \& Saúde; 2011:10

6 Fracassi AS, Gatto AR, Weber S, Spadotto AA, Ribeiro PW, Schelp AO. Adaptação para a língua Portuguesa e aplicação de protocolo de avaliação das disartrias de origem central em pacientes com Doença de Parkinson. Rev CEFAC. 2011;13:1056-1065

7 Carneiro D, Belo LR, Coriolano MGWS, Asano AGC, Lins OG. Qualidade de Vida em Disfagia: Uma revisão sistemática. Rev CEFAC. 2013;15:1347-1356

8 Smith SK, Roddam H, Sheldrick H. Rehabilitation or compensation: time for a fresh perspective on speech and language therapy for dysphagia and Parkinson's disease? Int J Lang Commun Disord 2012;47(04):351-364

9 Argolo N, Sampaio M, Pinho P, Melo A, Nóbrega AC. Swallowing disorders in Parkinson's disease: impact of lingual pumping. Int J Lang Commun Disord 2015;50(05):659-664

10 Kim YH, Oh BM, Jung IY, Lee JC, Lee GJ, Han TR. Spatiotemporal characteristics of swallowing in Parkinson's disease. Laryngoscope 2015;125(02):389-395

11 Nicaretta DH, Rosso AL, Mattos JP, Maliska C, Costa MMB. Dysphagia and sialorrhea: the relationship to Parkinson's disease. Arq Gastroenterol 2013;50(01):42-49

12 Fernandes GC, Socal MP, Schuh AFS, Rieder CRM. Clinical and Epidemiological Factors Associated with Mortality in Parkinson's Disease in a Brazilian Cohort. Parkinsons Dis 2015;2015:959304

13 Lee JY, Kim DK, Seo KM, Kang SH. Usefulness of the simplified cough test in evaluating cough reflex sensitivity as a screening test for silent aspiration. Ann Rehabil Med 2014;38(04):476-484

14 Ciucci MR, Barkmeier-Kraemer JM, Sherman SJ. Subthalamic nucleus deep brain stimulation improves deglutition in Parkinson's disease. Mov Disord 2008;23(05):676-683

15 Lengerer S, Kipping J, Rommel N, et al. Deep-brain-stimulation does not impair deglutition in Parkinson's disease. Parkinsonism Relat Disord 2012;18(07):847-853

16 Silbergleit AK, LeWitt P, Junn F, et al. Comparison of dysphagia before and after deep brain stimulation in Parkinson's disease. Mov Disord 2012;27(14):1763-1768

17 Hughes AJ, Daniel SE, Kilford L, Lees AJ. Accuracy of clinical diagnosis of idiopathic Parkinson's disease: a clinico-pathological study of 100 cases. J Neurol Neurosurg Psychiatry 1992;55(03): 181-184
18 Logemann JA, Veis S, Colangelo L. A screening procedure for oropharyngeal dysphagia. Dysphagia 1999;14(01):44-51

19 Padovani AR. Protocolo fonoaudiológico de introdução e transição da alimentação por via oral para pacientes com risco para disfagia orofaríngea (PITA) [Dissertação]. São Paulo: Faculdade de Medicina da Universidade de São Paulo; 2010

20 Luchesi KF, Kitamura S, Mourão LF. Dysphagia progression and swallowing management in Parkinson's disease: an observational study. Rev Bras Otorrinolaringol (Engl Ed) 2015;81(01):24-30

21 Crary MA, Mann GD, Groher ME. Initial psychometric assessment of a functional oral intake scale for dysphagia in stroke patients. Arch Phys Med Rehabil 2005;86(08):1516-1520

22 Furkim AM, Sacco ABF. Eficácia da fonoterapia em disfagia neurogênica usando a escala funcional de ingestão por via oral (FOIS) como marcador. Rev CEFAC. 2008;10:503-512

23 Hoehn MM, Yahr MD. Parkinsonism: onset, progression and mortality. Neurology 1967;17(05):427-442

24 Sundstedt S, Olofsson K, van Doorn J, Linder J, Nordh E, Blomstedt P. Swallowing function in Parkinson's patients following Zona Incerta deep brain stimulation. Acta Neurol Scand 2012;126(05): 350-356

25 Volkmann J, Albanese A, Kulisevsky J, et al. Long-term effects of pallidal or subthalamic deep brain stimulation on quality of life in Parkinson's disease. Mov Disord 2009;24(08):1154-1161

26 Tykocki T, Szalecki K, Koziara H, Nauman P, Mandat T. Quality of life and depressive symptoms in Parkinson's disease after subthalamic deep brain stimulation: a 2-year follow-up study. Turk Neurosurg 2013;23(03):379-384

27 Montel SR, Bungener C. Coping and quality of life of patients with Parkinson disease who have undergone deep brain stimulation of the subthalamic nucleus. Surg Neurol 2009;72(02):105-110, discussion 110-111

28 Mahdavi R, Malakouti SK, Shahidi GA, Parvaresh-Rizi M. The effects of bilateral subthalamic nucleus stimulation on cognitive and neuropsychiatric functions in Parkinson's disease: a casecontrol study (\#). Basic Clin Neurosci 2013;4(03):217-223

29 Gökbayrak NS, Piryatinsky I, Gavett RA, Ahmed OJ. Mixed effects of deep brain stimulation on depressive symptomatology in Parkinson's disease: a review of randomized clinical trials. Front Neurol 2014;5(05):154

30 Couto MI, Monteiro A, Oliveira A, Lunet N, Massano J. Depression and anxiety following deep brain stimulation in Parkinson's disease: systematic review and meta-analysis. Acta Med Port 2014;27(03):372-382

31 Jiang LL, Liu JL, Fu XL, et al. Long-term Efficacy of Subthalamic Nucleus Deep Brain Stimulation in Parkinson's Disease: A 5-year Follow-up Study in China. Chin Med J (Engl) 2015;128(18): 2433-2438

32 Combs HL, Folley BS, Berry DT, et al. Cognition and Depression Following Deep Brain Stimulation of the Subthalamic Nucleus and Globus Pallidus Pars Internus in Parkinson's Disease: A MetaAnalysis. Neuropsychol Rev 2015;25(04):439-454

33 Aono M, Iga J, Ueno S, Agawa M, Tsuda T, Ohmori T. Neuropsychological and psychiatric assessments following bilateral deep brain stimulation of the subthalamic nucleus in Japanese patients with Parkinson's disease. J Clin Neurosci 2014;21(09):1595-1598 